\title{
CONSTRUCTIVE ANALYSIS AND MODELLING OF A SINGLE NAVE CHURCHES: A PROPOSAL FOR S. SEBASTIANO (EN, ITALY)
}

\author{
ALESSANDRO LO FARO ${ }^{1 *}$, VALERIA CUSMANO ${ }^{1}$, BARTOLOMEO PANTÒ ${ }^{2}$ AND \\ FRANCESCO CANNIZZARO ${ }^{1}$ \\ ${ }^{1}$ Department of Civil Engineering and Architecture (DICAR) \\ University of Catania \\ Via Santa Sofia 64, 95123 Catania, Italy \\ e-mail: alessandro.lofaro@darc.unict.it, valeria.cusmano@phd.unict.it, francesco.cannizzaro@unict.it, \\ www.dicar.unict.it $(*$ corresponding author) \\ ${ }^{2}$ Department of Civil and Environmental Engineering \\ Imperial College London \\ South Kensington Campus, London SW7 2AZ, United Kingdom \\ email: b.panto@imperial.ac.uk,www.imperial.ac.uk/civil-engineering
}

Keywords: Historical Structure, Masonry church, Discrete Macro-element, Conservative restoration, Nonlinear analysis, Strengthening techniques

Abstract. The seismic events occurred in Italy in the last decay (L'Aquila 2009, Emilia 2012, Central Italy Earthquakes 2016/2017) have caused the collapse of numerous historical buildings and monuments with loss of life and irreversible damages to the cultural heritage. An effective seismic prevention would avoid, or delay, the most frequent collapse mechanisms. However, it requires a correct interpretation of the structural mechanical behavior. With regard to the traditional masonry buildings, this issue presents a high level of complexity due to the uncertainties related to the materials and the constructive techniques. Furthermore, historic buildings are often the result of several modifications that induce significant structural irregularities. A possible analysis strategy is provided by a discrete macro-element modelling (DMEM) approach which is able to simulate the global behavior of traditional fabrics, if supported by an adequate level of historic, geometrical, constructive and structural knowledge. In this paper a multidisciplinary procedure is applied to the church of S. Sebastiano in Regalbuto (Italy), considered as case study. This procedure is composed of three steps: the knowledge phase in which the constructive apparatus and the static schemes are identified, the modelling phase and the assessment phase in which the current safety level of the building and possible interventions that would be compatible with its cultural instance, are individuated. According to the followed procedure, different scenarios of intervention, characterized by increasing levels of benefit and invasiveness, are considered. For each scenario, non-linear static push-over analyses are performed, to evaluate the benefits and identify the structural critical issues, useful to individuate the next scenario. The obtained results are presented and discussed both in terms of capacity curves and failure mechanisms. 


\section{INTRODUCTION}

The seismic protection of a historical masonry building is usually pursued not only aiming at the safety of the structure, at minimizing the human losses and at limiting the damage to its content, but also adopting techniques respectful of the original constructive concepts and employing reversible strategies which are aspects commonly included in the retrofitting design process.

When it comes to churches the choices are even more difficult and strategic for several additional reasons; the relevance of the building with respect to the loss of human lives is very high, but the structure also assumes an additional importance because of its historical, social and artistic value. A further aspect to be considered is that churches do not behave as ordinary buildings from a structural point of view; indeed, they usually present tall walls as well as lack of slabs and spinal walls which prevent to attribute to such structures a box behaviour, typical of ordinary buildings. For the mentioned reasons, the walls of masonry churches and their façades exhibit a keen tendency to overturn, and the out-of-plane mechanisms are usually limited by the presence of tie rods and buttresses. However, traditional seismic protection devices cannot be considered as general and thorough retrofitting strategies, also in the light of the stringent standards introduced with the recent codes [1,2]. In particular, in some cases the adoption of reinforcements based on steel members and the application of fiber-reinforced textiles are strategies commonly adopted by practitioners. Such approaches imply an increasing level of invasiveness of the strengthening interventions, which have to be

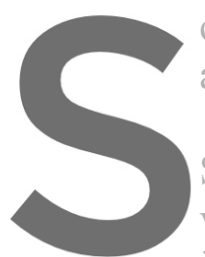
carefully calibrated and conservation of the

In this paper, a

Sebastiano church in view, through a detaile identifying the principal building elements
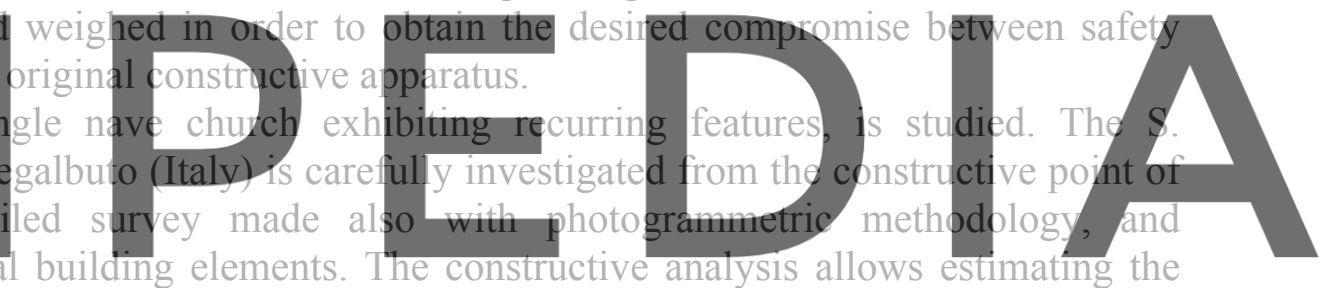
mechanical properties adopted in the structural model by means of the rules proposed in [3]

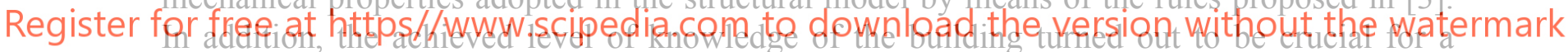

more conscious choice of the retrofitting strategy.

Then, a giobal numerical model aiming at the assessment of the seismic vuinerability of the church is implemented. The adopted discrete macro-element modelling (DMEM) strategy $[4,5]$ is able to perform reliable nonlinear static analyses with a limited computational burden and has already been applied to masonry churches [6,7]. Nonlinear pushover analyses have been conducted on the model in order to evaluate the current seismic safety of the church.

Then, three different retrofitting scenarios have been considered and modelled, with increasing levels of safety and invasiveness. The considered techniques include traditional and innovative strategies, which are duly modelled, and their effectiveness is properly estimated. The three different possible strengthening approaches are intended to be a contribution towards a reasoned design process, which should be an enlightened compromise among safety, conservation and cost of the intervention, as better clarified in the comparative analysis reported at the end of the paper and in the conclusive section. 


\section{TOWARDS A REASONED CHOICE OF RETROFITTING STRATEGIES OF HISTORICAL MASONRY BUILDINGS}

The choice of the best possible strengthening strategy for masonry buildings represents a topic with a high practical interest for which no general rule can be employed. This difficulty becomes even harder for historical masonry buildings, since additional aspects, such as the preservation of the cultural value of the building and the possible high loss of human lives in case of seismic events, have to be accounted for.

Usually the strengthening techniques to be applied are selected according to basic principles of the restoration of buildings. The adopted techniques must respect the criteria of reversibility, low invasiveness, minimum intervention, recognizability of the original structural scheme, chemical, physical and mechanical compatibility, durability [8]. Such principles are nowadays universally accepted and followed. Nevertheless, there are some additional aspects which are also accounted for when conceiving a strengthening intervention, that is the economic cost and the achieved level of safety.

To this purpose, in this paper a methodology to get to a reasoned choice of the retrofitting strategy for historical masonry building, is proposed. In particular, three stages are identified.

The first stage includes the constructive assessment of the building in the current conditions and the seismic assessment through a global numerical model on which nonlinear static analyses are performed. This stage aims at identifying the original structural scheme of the building, at evaluating the mechanical properties of the masonry and at assessing the main

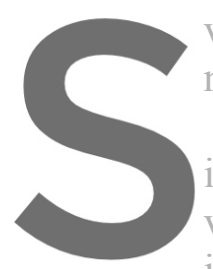
vulnerabilities of the structure through the in
numerical analyses.
The second stage consists in designing se
invasiveness and effectivenes to apply on the
vulnerabilities of the building. For each level o
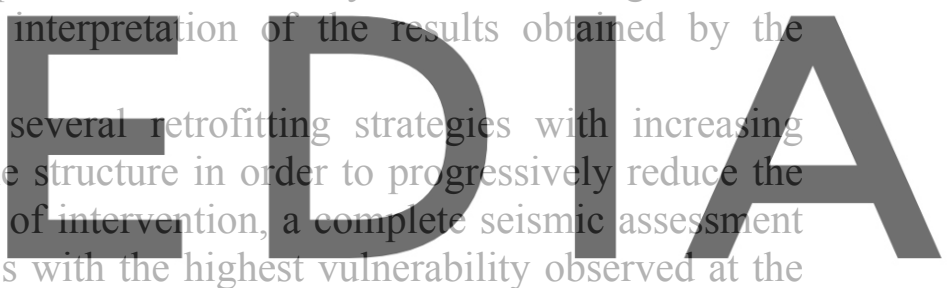
is needed, aiming at removing the weaknesses with the highest vulnerability obs

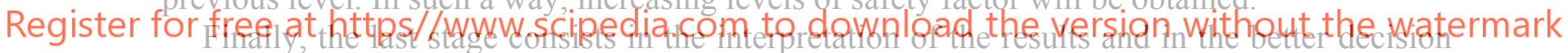

for the strengthening strategy to be adopted. In particular, safety factor, economic cost and invasiveness of the intervention have to be weighted evaluating pros and cons of each level of considered strengthening contribution. The proposed methodology aims at more aware choices of the intervention, able to account for the main aspects which should guide a retrofitting design of historical masonry building.

In the following section the briefly described methodology is applied to a meaningful case study, that is the S. Sebastiano church in Regalbuto (Italy).

\section{THE CASE STUDY: S. SEBASTIANO CHURCH}

The study of traditional buildings must be framed in the context of an analysis and design process that is very different from the usual ones followed, for example, in the field of new construction. Firstly, when built heritage is considered, an in-depth knowledge of the building is required. Moreover, since in the case of historic masonry buildings are usually of complex nature, it is necessary to get all the possible information according to different points of view in order to read and understand all signs that time has left on them. Therefore, for each 
building, its own story (regarding its construction and every transformation occurred on it) has to be reconstructed; in addition, a geometric-spatial investigation of the current state of the building and a technical-constructive analysis must be carried out aimed at identifying material, processes and constructive technologies. Only after having collected all the mentioned data, it will be possible to define compatible strategies to ensure the conservation of the building.

\subsection{The constructive assessment of the church}

San Sebastiano church is located in the homonymous district in Regalbuto, a small town in the province of Enna (Sicily, southern Italy) of about six thousand inhabitants. There is inadequate information regard its construction. It was probably built between the end of $14^{\text {th }}$ century and the beginning of $15^{\text {th }}$ century and it was a confraternity church strongly desired by the faithful. The homonymous neighbourhood develoned around it after its construction,

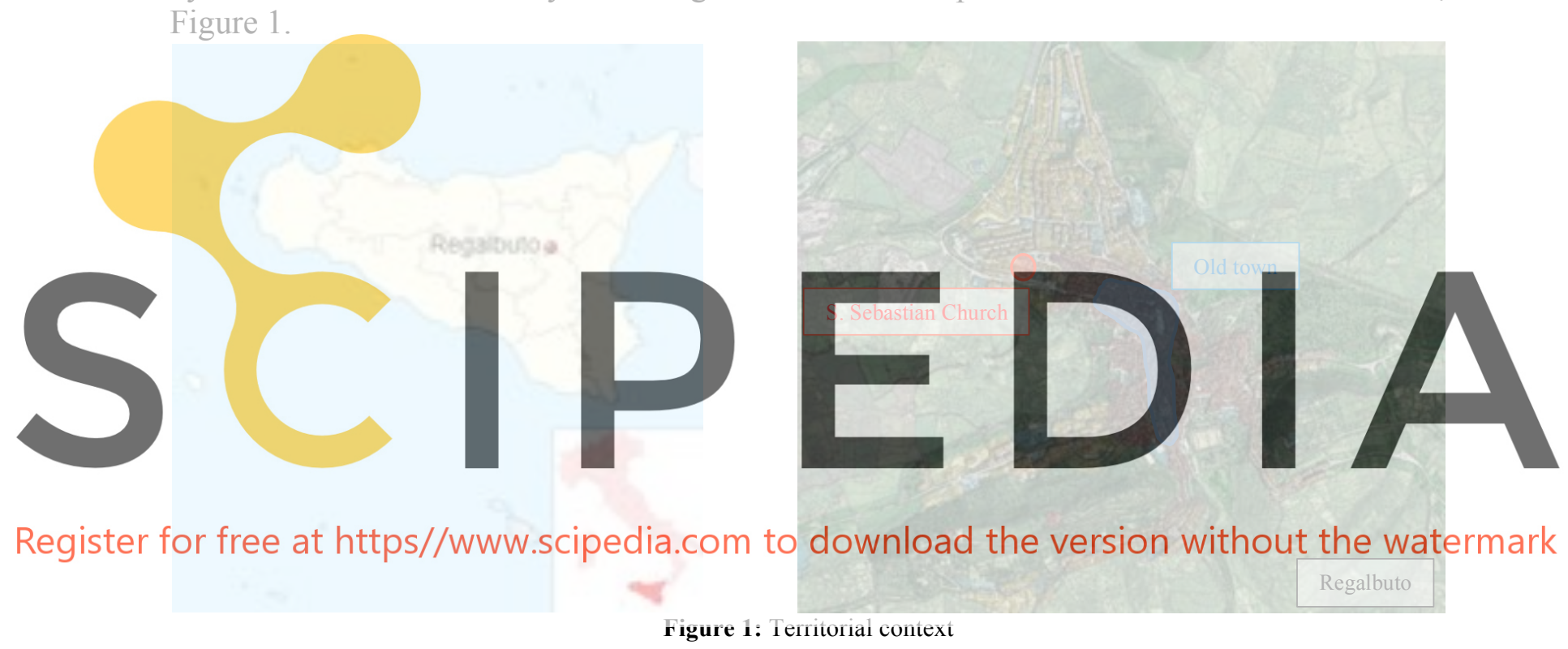

The church is structurally isolated and has a spatial organization that can be divided into three parts: single nave church having a longitudinal development (1), a lower adjacent volume which houses the former oratorio (2) and the bell tower (3), Figure 2a. The size of the nave is $24.50 \times 8.00 \mathrm{~m}$. The horizontal closure is made by a masonry barrel vault whose minimum and average thicknesses are equal to $15 \mathrm{~cm}$ and $18 \mathrm{~cm}$, respectively. Above the masonry vault there is a pitched roof. The church is entirely built with sandstone ashlars units with lime mortar, often used in the nearby area for similar historic buildings, Figure 2b. The thickness of the walls is variable: nave's walls have a thickness of $90 \mathrm{~cm}$; lower volume's walls are 80 $\mathrm{cm}$-thick and the bell tower's walls have a thickness of $60 \mathrm{~cm}$.

No documents have been found attesting next interventions on the building. However, it is conceivable to believe that some static aids, such as tie rods in the main vault and buttress on one of the longitudinal walls, have been inserted after the construction of the building, Figure 3. The spatiality of the church was determined by direct survey, Figure $4 \mathrm{a}$, and by the use of structure from motion methodology, Figure $4 \mathrm{~b}$. 


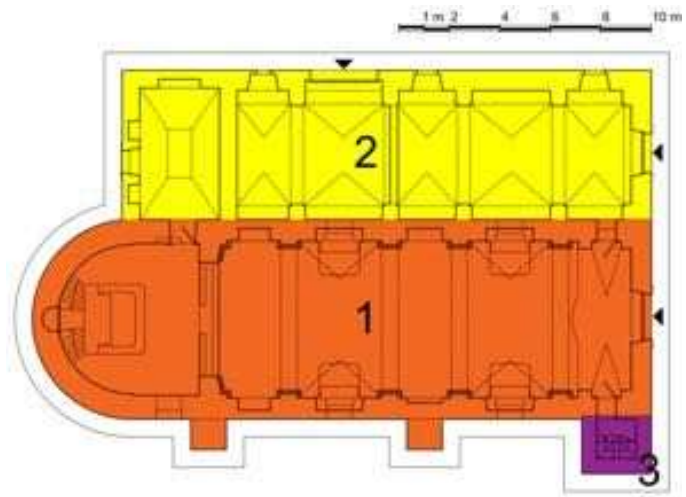

(a)

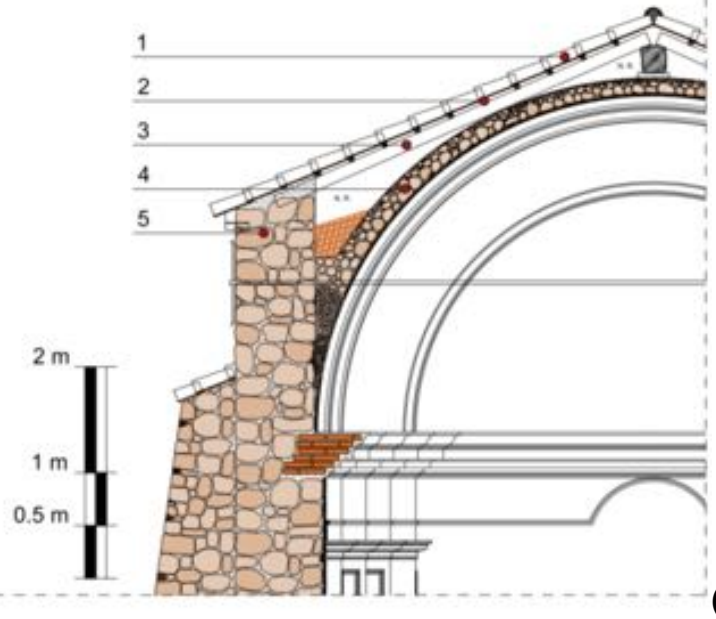

Figure 2: (a) Spatial organitazion of the building: 1 Church; 2 Former oratorio; 3 Bell tower. (b) Constructive section: Sicilian tiles; 2 Wooden trestles; 3 Wooden beam; 4 Masonry barrel Vault; 5 Masonry with badly connected buttress: irregular sanstone ashlars and lime

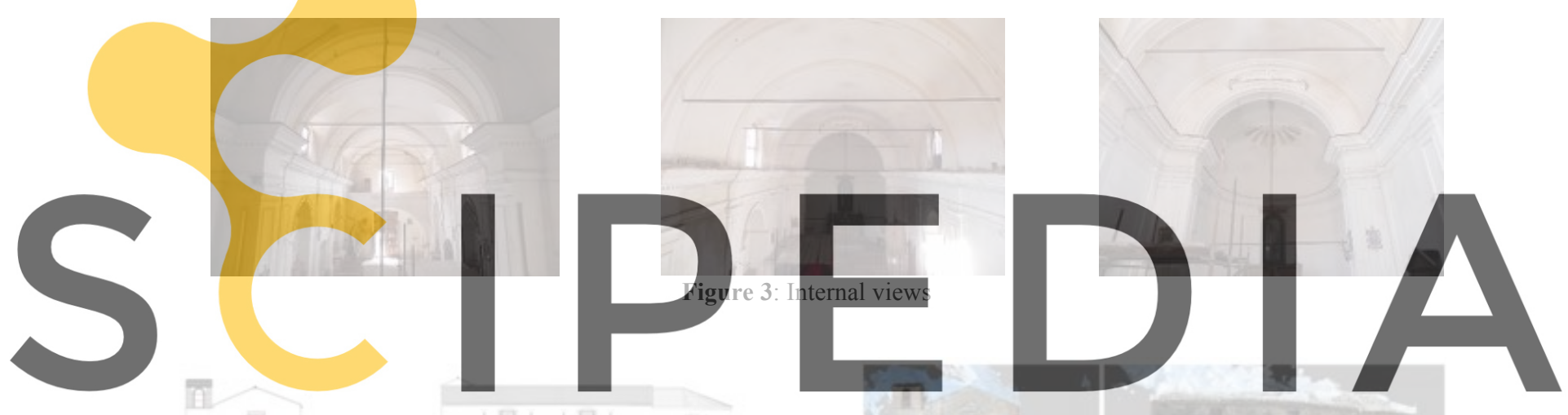

Register for free at https//www.scipedia.com to download the version without the watermark

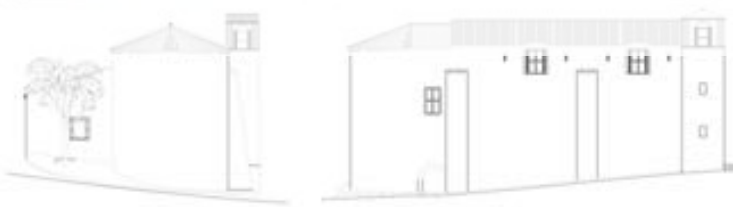

(a) (b)
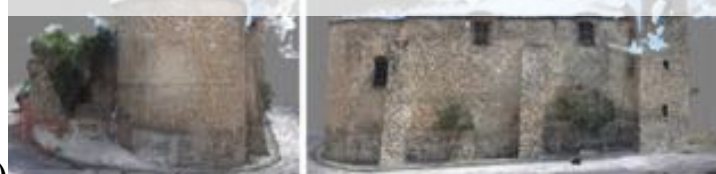

Figure 4: (a) External façades and (b) church model obtained with structure from motion methodology

\subsection{The assessment of the mechanical properties through the quality of the masonry media}

For the identification of masonry's mechanical characteristics, it was carried out an analysis of masonry quality, based on visual examination, that allowed us to express a qualitative overall judgment regarding compliance with the "rules of art". The judgment was expressed in terms of "Respected" ("R"), "Not respected" ("NR"), "Partially respected" ("PR") as proposed by Borri et al. (2015) [3]. This evaluation was carried out through the so-called "scoring method". This method involves the characterization of a wall panel subject to 
different load conditions. In fact, the parameters that define the "rules of art" influence in a different way the response of the wall according to its load condition. The result is an index called IQM (Index of Quality of Masonry) for each applied load. Through this index a category is assigned to the masonry. There are three categories: category " $\mathrm{A}$ " (good behavior of masonry), category " $B$ " (medium behavior of masonry), category " $C$ " (insufficient behavior of masonry). The assigned score for each load condition is highlighted in Table 1 . The IQM evaluation is aimed at obtaining an estimation of the mechanical parameters when there is no data available from in situ tests. A range of plausible values for three mechanical parameters, Young's modulus $(E)$, compressive strength $\left(f_{m}\right)$ and shear strength $\left(\tau_{0}\right)$, is associated, through an empiric relationship, to each value of IQM is associated, Figure 5; the considered upper and lower bounds of the mechanical properties are identified in blue and red, respectively. The analytical functions of the empiric correlations, previously recalled, are reported in [3]. The grid of scores for the vertical actions (suitable to determine the compressive strength and the Young's modulus) and for the in-plane actions (employed to estimate the shear strength) are summarized in the following Table 1, where the scores given to masonry media of the case study are highlighted. The value of IQM is computed as $\mathrm{IQM}=$ RE. EL $\times($ OR. +P. D. +F.EL. +S.G. +D.EL. +MA. $)$ for each load condition and the obtained ranges of the mechanical properties result: $f_{m}=1.38-2.39 \mathrm{~N} / \mathrm{mm}^{2} ; \tau_{0}=0.028-$ $0.043 \mathrm{~N} / \mathrm{mm}^{2} ; E=743.22-1093.09 \mathrm{~N} / \mathrm{mm}^{2}$.

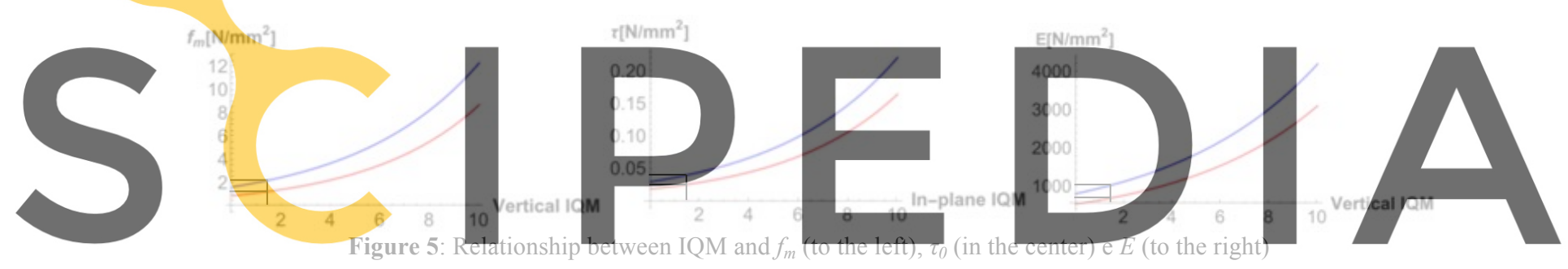

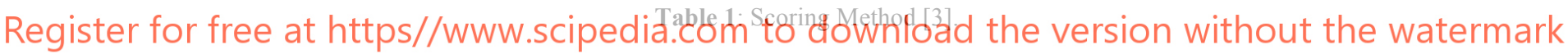

\begin{tabular}{ccccccc}
\hline Parameter & \multicolumn{3}{c}{ Vertical action } & \multicolumn{3}{c}{ In-plane action } \\
\hline & $\mathbf{N R}$ & $\mathbf{P R}$ & $\mathbf{R}$ & $\mathbf{N R}$ & $\mathbf{P R}$ & $\mathbf{R}$ \\
\hline O.R. (Horizontality of the rows) & $\underline{\mathbf{0}}$ & 1 & 2 & $\underline{\mathbf{0}}$ & 0.5 & 1 \\
\hline P.D. (Presence of diatons) & $\underline{\mathbf{0}}$ & 1 & 1 & $\underline{\mathbf{0}}$ & 1 & 2 \\
\hline F.EL. (Resistant elements shape) & 0 & $\underline{\mathbf{1 . 5}}$ & 3 & 0 & $\underline{\mathbf{1}}$ & 2 \\
\hline S.G. (Vertical joints offset) & $\underline{\mathbf{0}}$ & $\mathbf{0 . 5}$ & 1 & $\underline{\mathbf{0}}$ & 1 & 2 \\
\hline D.EL. (Resistant elements size) & 0 & $\underline{\mathbf{0 . 5}}$ & 1 & 0 & $\underline{\mathbf{0 . 5}}$ & 1 \\
\hline MA. (Mortar quality) & 0 & $\underline{\mathbf{0 . 5}}$ & $\mathbf{2}$ & 0 & $\underline{\mathbf{1}}$ & 2 \\
\hline RE.EL. (Resistance of stone elements) & 0.3 & $\underline{\mathbf{0 . 7}}$ & 1 & 0.3 & $\underline{\mathbf{0 . 7}}$ & 1 \\
\hline IQM & & $\mathbf{1 . 7 5}$ & & & 1.75 &
\end{tabular}

\section{SEISMIC ASSESSMENT OF THE CHURCH}

In this section a numerical assessment of the seismic safety of the church is performed. In particular, in the first subsection the adopted numerical model based on a DMEM approach is briefly recalled. Then, after evaluating the safety of structure in its current state, three possible strengthening scenarios are described and their effectiveness is numerically assessed and compared to each other. 


\subsection{The adopted numerical model}

In this work a numerical strategy based on a discrete macro-model, already available in the literature, is employed for the nonlinear numerical simulations of both unreinforced and FRP reinforced masonry structures. According to this approach, the masonry is modeled through an equivalent mechanical scheme constituted by a hinged quadrilateral endowed with one or two diagonal links to rule the diagonal shear cracking, and interacting with contiguous elements along its four edges by means of nonlinear discrete interfaces which govern the flexional and the sliding behavior. Each discrete interface is made of a single or multiple (according to the model) rows of transversal links for the flexional behavior and single or multiple (according to the model) sliding links. The different stages of this discrete element are reported in Figure 6. This approach was originally introduced for modeling the in-plane behavior of Unreinforced Masonry Structures [9], Figure 6a. This plane element possesses four degrees of freedom, a single row of transversal links and a single in-plane sliding link, and is able to model the main failure mechanisms of the masonry in its own plane, as long as a proper calibration procedure of the links is adopted. Two subsequent upgrades were achieved to expand the potentialities of the approach. First, the out of plane (spatial) behavior, typical of historical constructions, was added [10] by considering additional rows of transversal links and two additional out-of-plane sliding links (able to govern the out of plane shear behavior and the torsion), thus enabling the out of plane degrees of freedom, Figure $5 \mathrm{~b}$. Subsequently, a further upgrade was introduced considering a shell macro-element characterized by an irregular geometry, variable thickness along the element and skew interfaces [11] in order to deal with structures with a curved geometry, such as vaults and
domes, Figure 6c. The calibration procedures, concerning the mechanical properties of the
links, were properly extended in order to account for the more compligated geometry of the
element, but keeping the same general philosophy. Numerical and experimental validations of
the proposed approach, with reference to full scale structures can be found in [5]. Finally, in order to model the interaction with FRP strips a textile, the model was further

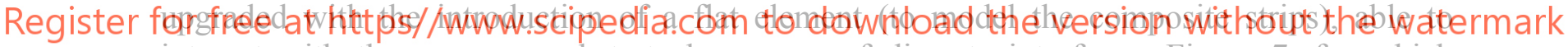
interact with the masonry substrate by means of discrete interfaces, Figure 7, for which specific calibration procedures were duly introduced and validated [12]
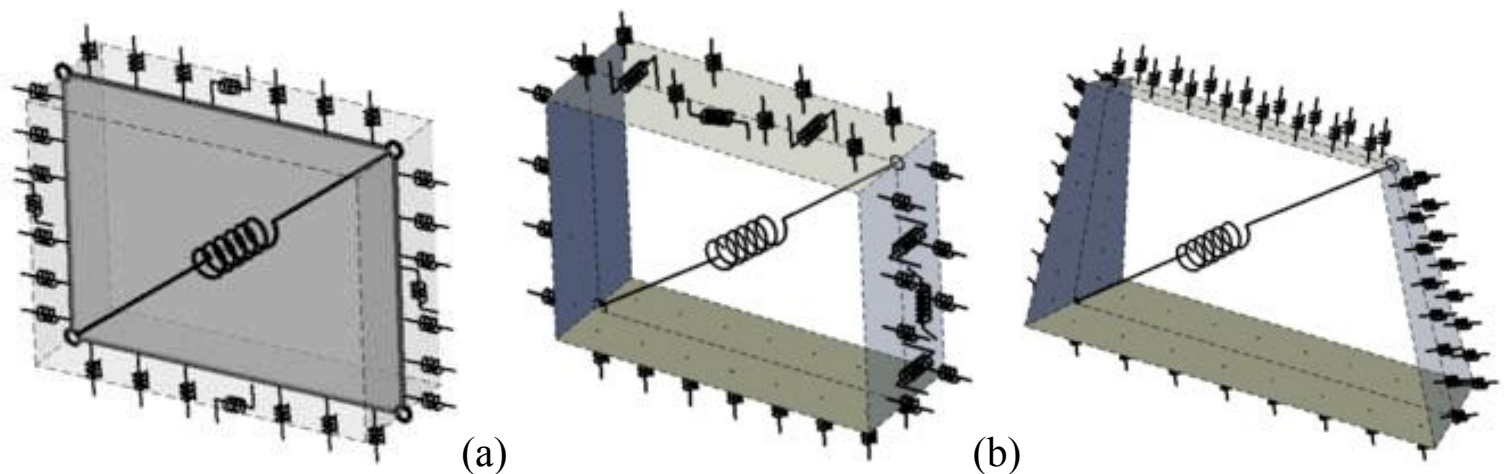

(c)

Figure 6: Layout of the macro-element adopted for masonry at its three stages: (a) plane element, (b) spatial regular element and (c) three-dimensional element for curved structures. 


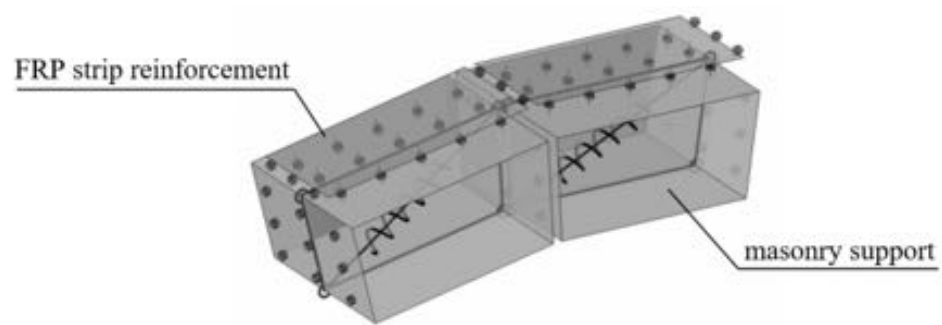

Figure 7: Layout of the interaction between flat FRP discrete element and masonry substrate [12].

\subsection{Numerical results and comparative analysis of different strengthening scenarios}

The entire church was modelled by a discrete $3 \mathrm{~d}$ model developed by using an average mesh size of about $100 \mathrm{~cm}$. This mesh of elements has been refined when it was necessary (for example for arched openings). The numerical model is made of 1159 quadrilateral shear deformable elements, 32 triangular shear rigid elements and 2388 interfaces, which are associated to a total amount of 8305 degrees of freedom. The model discretization has been chosen with the aim of combining reliable results with a limited computational burden. In Figure 8 two significant views of the model implemented in the software HiStrA [13] are depicted, and the adopted reference system is identified.

In addition to the self-weight of the elements, overloads associated to non-structural elements are applied as line loads, according to the characteristic values reported in Tables 2. The diagonal shear mechanism is calibrated according to the Turnsek-Cacovic dominium
while the sliding mechanisin is manged by the Mohr-Coulomb criteria (cnabled in
correspondence of the connedtion between the buttresses and longitudinal walls only). The
complete set of the mechanical paraneters adopted in the analyses, estimated according the
masonry characterization reported in the previous section, are reported in Table 3, where
average values with respect to the identified ranges are selected.

Register for free at https//www.scipedia.com to to Aplied hoads the version without the watermark

\begin{tabular}{cccc}
\hline Central nave & Former oratorio & Bell tower & Barrel vault \\
\hline $2.49 \mathrm{kN} / \mathrm{m}$ & $3.88 \mathrm{kN} / \mathrm{m}$ & $1.17 \mathrm{kN} / \mathrm{m}$ & $22.64 \mathrm{kN} / \mathrm{m}$ \\
\hline
\end{tabular}
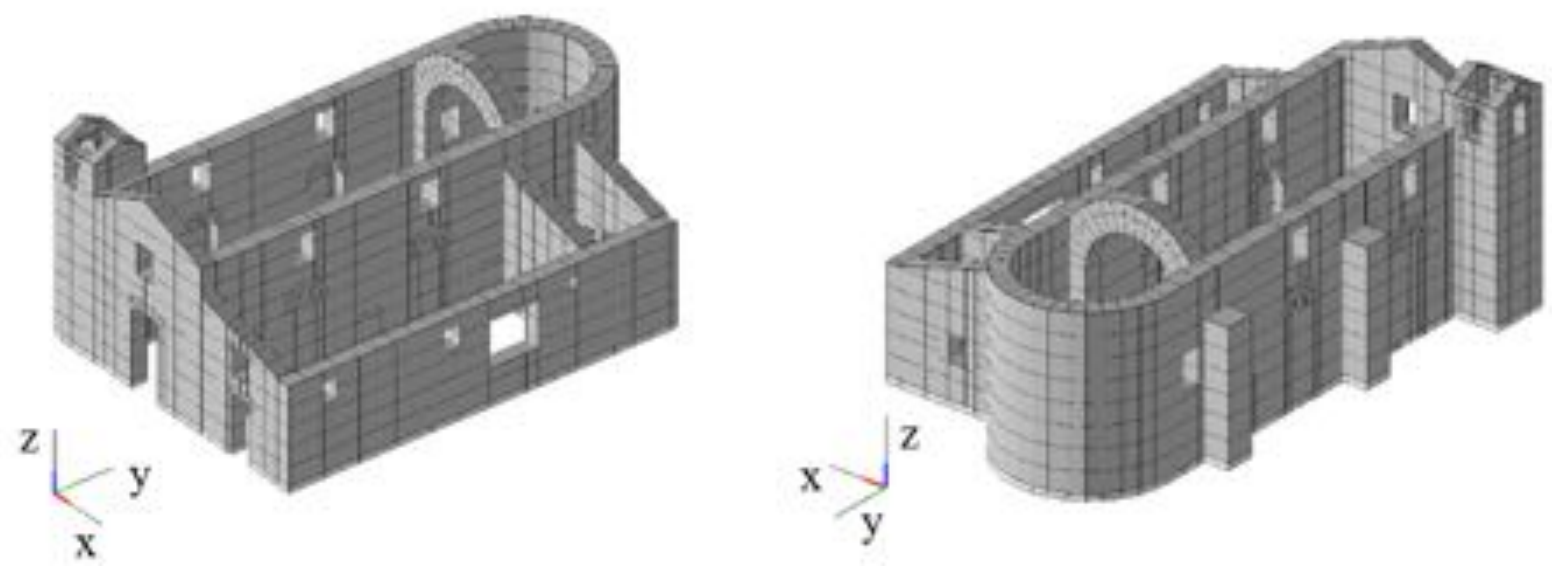

Figure 8: Numerical model and adopted reference system. 
Table 2: Mechanical parameters adopted in the numerical model

\begin{tabular}{|c|c|c|c|c|c|c|c|c|}
\hline \multirow{3}{*}{$E\left[\mathrm{~N} / \mathrm{mm}^{2}\right]$} & \multicolumn{4}{|c|}{ Rocking mechanism } & \multirow{2}{*}{\multicolumn{2}{|c|}{ Shear mechanism }} & \multirow{2}{*}{\multicolumn{2}{|c|}{ Sliding mechanism }} \\
\hline & \multicolumn{2}{|c|}{ Tensile } & \multicolumn{2}{|c|}{ Compression } & & & & \\
\hline & $\begin{array}{c}f_{t} \\
{\left[\mathrm{~N} / \mathrm{mm}^{2}\right]}\end{array}$ & $\boldsymbol{G}_{t}[\mathrm{~N} / \mathrm{mm}]$ & $\begin{array}{c}f_{m} \\
{\left[\mathrm{~N} / \mathrm{mm}^{2}\right]}\end{array}$ & $\begin{array}{c}\boldsymbol{G}_{\boldsymbol{c}} \\
{[\mathrm{N} / \mathrm{mm}]}\end{array}$ & $\boldsymbol{G}\left[\mathrm{N} / \mathrm{mm}^{2}\right]$ & $\tau_{0}\left[\mathrm{~N} / \mathrm{mm}^{2}\right]$ & c & $M$ \\
\hline 950 & 0.035 & 0.01 & 1.88 & 1 & 500 & 0.035 & 0.15 & 0.7 \\
\hline
\end{tabular}

The first 8 fundamental periods with the effective mass ratios and the cumulated participating masses along the transversal (x) and the longitudinal directions (y) are listed in the following Table 4. In Figure 9 the modes with highest participating mass are reported, showing the absence of global modes and how the longitudinal walls are keen to the out-of-plane response. Nonlinear static analyses were performed considering mass proportional load distributions along the four main directions of the building. The results are reported in terms of capacity curves, Figure 10, and failure mechanisms, Table 5 (first row). The capacity curves are reported in terms of top displacement of the façade (point 1) and longitudinal walls (point 2) versus the base shear coefficient (base shear normalized by the total weight). The collapse mechanisms show that the longitudinal walls and the façade are keen to overturn due to the lack of horizontal elements and the inefficacy of the buttresses; the base shear coefficients range between 0.25 in the transversal direction to approximately 0.37 in the longitudinal direction (pushing the façade).
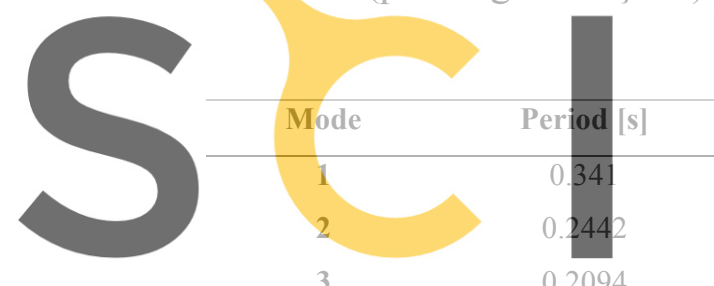

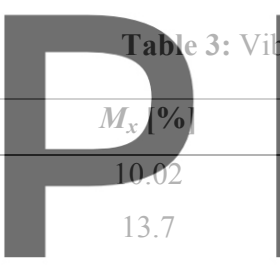

4.8

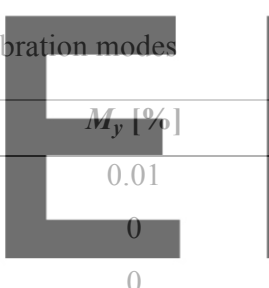

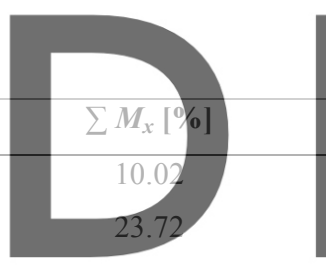

28.52

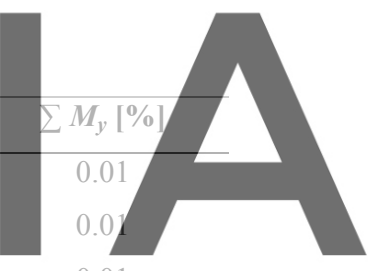

0.01

Register for free at https/AwW 50.1665

60.1372

$7 \quad 0.1318$

11.92

0.94

7

0.1318

1.83

8.89

40.5

1.85

8

0.1264

0.03

5.2

42.33

10.74

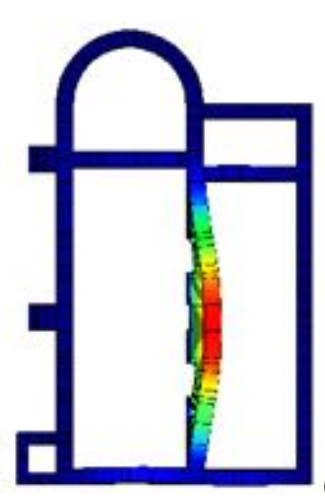

(a)

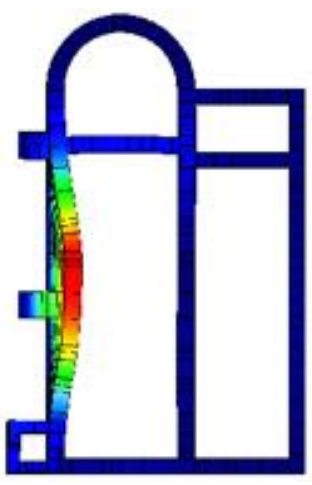

(b)

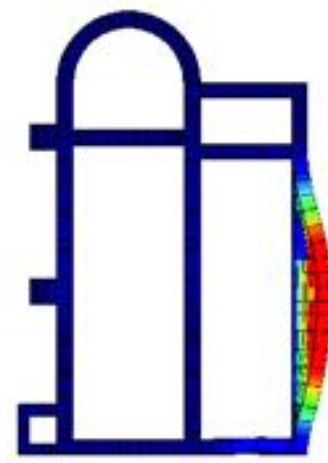

(c)

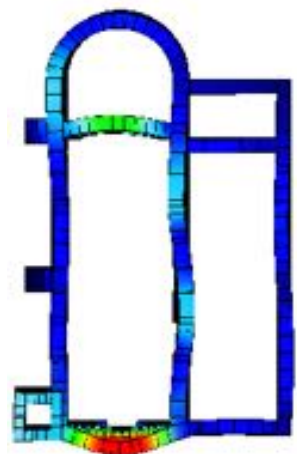

Figure 9: Vibration modes: (a) first, (b) second, (c) third and (d) seventh 
In order to increase the seismic global behaviour of the structure, three different retrofitting scenarios have been considered and modelled. The first scenario, Figure 10a, consists in restoring and effective connection of the buttresses with the longitudinal walls (no sliding can occur in the numerical model) and in the re-tensioning of already existing tie rods; the second scenario, Figure 10b, includes the complete replacement of the roof with a steel and wooden roof connected to the masonry with a reinforced masonry ring beam; the last strengthening scenario, Figure 10c, consists in the use of fiber-reinforced composite material with a lime mortar matrix on the main façade of the building. This scenario is compatible with the cultural instance of the building because the fiber strips would be hidden by a new lime plaster over the facade. The three scenarios have been conceived as 'additional' in that the second scenario includes the intervention of the first one, and the third scenario also includes those associated to the first two strengthening scenarios.

The capacity curves of the reinforcing scenario are reported in Figure 11 whereas the collapse mechanisms are reported in Table 5 (second to fourth rows). The second retrofitting scenario, ensuring an effective horizontal constraint at the roof level, provides an evident contribution to the global behaviour of the structure. Consequently, both the global lateral strength and ductility capacity of the structure increased when compared to the unreinforced configuration. Moreover, the second scenario avoids the global out-of-plane failure of the façade, predicted in the unreinforced state. The first and the third scenarios do not provide a significant contribution to the global response. However, the third scenario reduces the out-of-plane

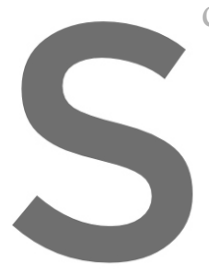
displacements of the
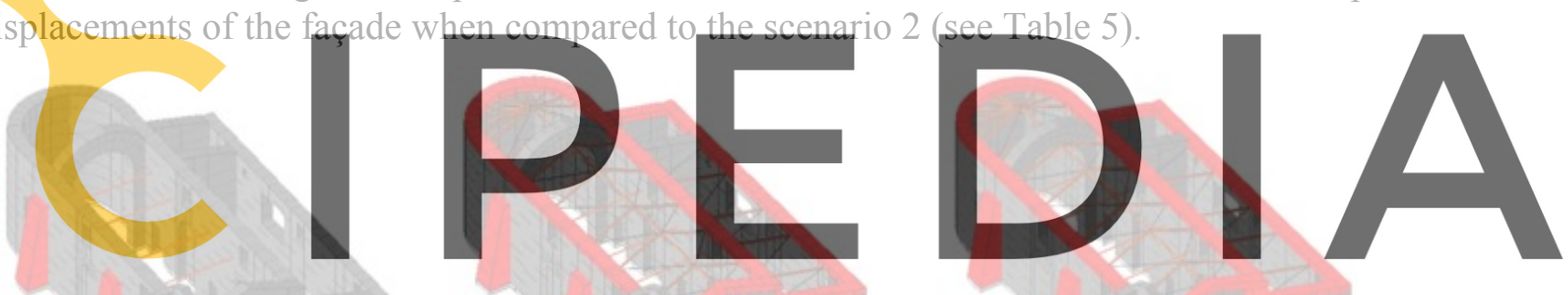

Register for free at https//www.scipedia.com to download the version without the watermark

(a)

(b)

(c)

Figure 10: Retrofitting scenarios: (a) Scenario 1, (b) Scenario 2 and (c) Scenario 3

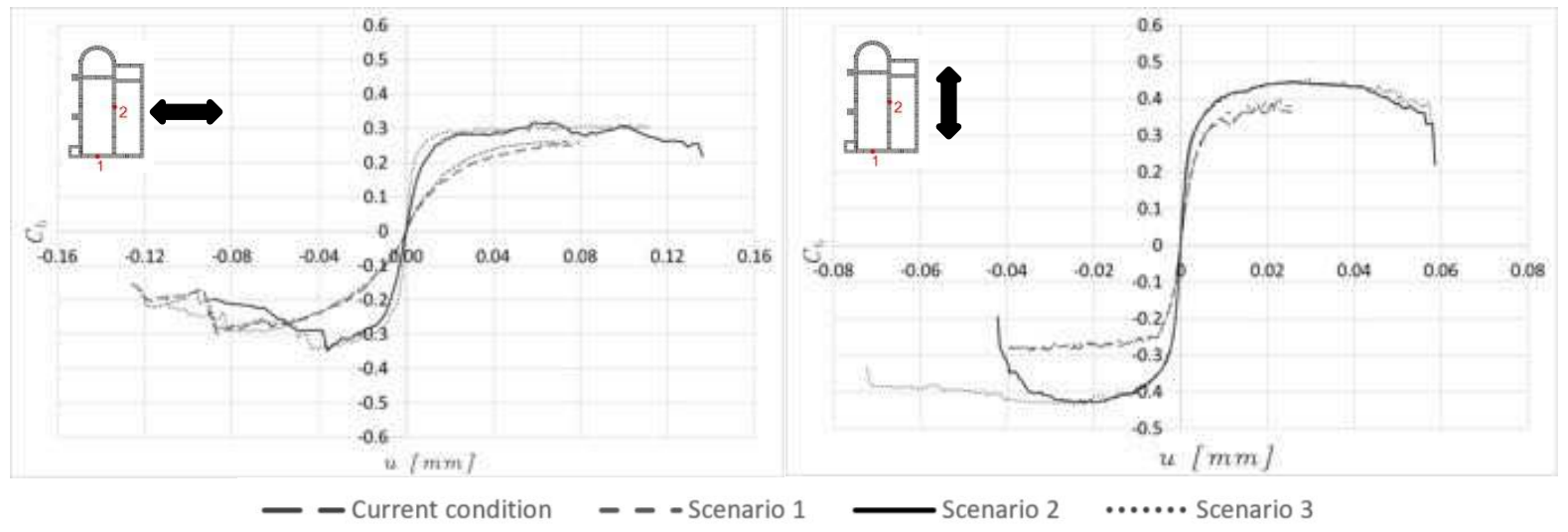

Figure 11: Capacity curves 
Table 5: Failure mechanism

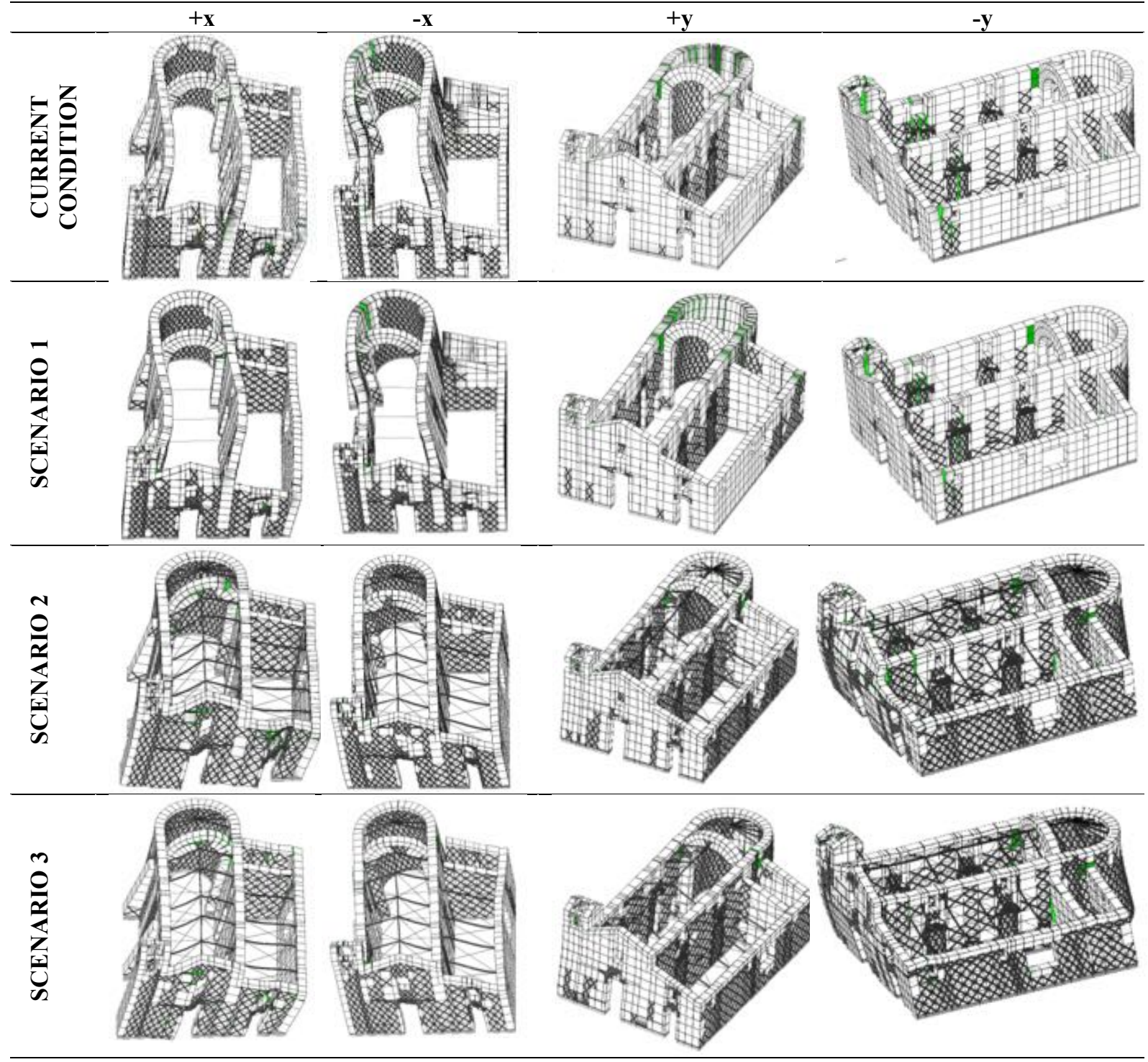

\section{CONCLUSIONS}

In this study a comprehensive analysis of a monumental structure is presented. The chosen case study is analyzed from the constructive point of view, identifying the main features of the building. Then, a numerical model is implemented in the framework of a DMEM environment to assess its safety with respect to seismic conditions, and nonlinear analyses are performed considering the current configuration. Based on the obtained results, three different strengthening scenarios are modelled and analyzed. The three scenarios are conceived as additive strategies, with the aim of identifying the progressive benefits and invasiveness. In particular, the first and the second interventions are selected considering traditional techniques (restoring the original connection between orthogonal walls, re-tensioning the existing tie rods, inserting a masonry ring beam). Although the traditional techniques, whose 
application was found inside the church, showed their capability to limit some of the vulnerabilities of the church, in the last considered scenario, the application of fiberreinforced strips in the main façade has been included in the overall retrofitting strategy. This progressive strengthening design was proposed as a reasoned methodology able to identify the impact to the global safety of the building of each of the considered measures both in terms of structural improvements, economic cost and invasiveness, and might be applied to other historical buildings. Their weaknesses can be rarely removed with a single measure, but rather require a comprehensive design, starting with a deep preliminary knowledge, and including several, but always compatible, strengthening methodologies [14].

\section{REFERENCES}

[1] Eurocode 8: Design of structures for earthquake resistance - Part 3: General rules, seismic actions and rules for buildings, Design Code EN 1998-3, 2005.

[2] NTC 2008, Decreto Ministeriale 14/1/2008: Norme tecniche per le costruzioni., Ministry of Infrastructures and Transportations, 2008.

[3] Borri A., Manuale delle murature storiche, Vol. I., D.E.I. Editrice, (2011).

[4] Cannizzaro, F., Pantò, B., Caddemi, S. and Caliò. I., A Discrete Macro-Element Method (DMEM) for the nonlinear structural assessment of masonry arches. Eng. Struct. (2018) 168:243-56.

[5] Caddemi, S., Caliò, I., Cannizzaro, F. and Pantò, B., New frontiers on seismic modeling of masonry structures. Frontiers in Built Environment (2017) 3, art. no. 39.

[6] Pantò, B., Cannizzaro, F., Caddemi, S. and Caliò, I., 3D macro-element modelling approach for seismic assessment of historical masonry churches. Advances in Engineering Software (2016) 97:40-59.

[7] Pantò, B., Giresini, L., Sassu, M. and Caliò, I., Non-linear modeling of masonry churches through a discrete macro-element approach. Earthquake and Structures (2017) 12 (2):223-236.

[8] Sanpaolesi P., Discorso sulla metodologia generale del restauro dei monumenti, Edam, (1973), pp. 111-118.

[9] Caliò, I., Marletta M., Pantò, B., A new discrete element model for the evaluation of the seismic behaviour of unreinforced masonry buildings. Eng Struct (2012) 40:237-338.

[10] Pantò, B., Cannizzaro, F., Caliò, I. and Lourenço PB. Numerical and experimental validation of a 3D macro-model for the in-plane and out-of-plane behaviour of unreinforced masonry walls. Int J Architect Heritage (2017).

[11] Calió, I., Cannizzaro, F., and Marletta, M., A discrete element for modeling masonry vaults. Adv. Mater. Res. (2010)133-134:447-452.

[12] Pantò, B., Cannizzaro, F., Caddemi, S., Caliò, I., Chácara, C. and Lourenço, PB., Nonlinear modelling of curved masonry structures after seismic retrofit through FRP reinforcing. Buildings (2017) 7:79.

[13] HiStrA (Historical Structure Analysis) Release 17.2.3,” ed. Catania, (2015).

[14] Lo Faro A., Contrafatto L., Di Stefano A. L'Aquila's single nave churches and 2009's earthquake: knowledge, modeling, intervention. In: Di Giuseppe E. et al. (Eds.): ColloquiA.Te 2017. Demolition or Recostruction?, EdicomEdizioni, (2017), pp. 263-274. 